\title{
Enfermedad injerto contra huésped (EICH). Caso clínico con expresión en mucosa bucal
}

\author{
Gonzalo Rojas A ${ }^{1,3 a}$, Néstor G onzález $\mathrm{G}^{2}$, \\ Cristián Venables $\mathbf{G}^{3 a}$, Daniel Araos $\mathbf{H}^{2}$.

\section{Graft versus host disease with oral involvement. Report of one case}

Graft versus Host Disease (GVHD) is a common complication in allogenic bone marrow transplants and in some cases, it involves the oral mucosa. Therefore, the appropriate diagnosis and timely treatment is essential to prevent local complications which interfere with normal oral functions and facilitate infection spread. We report a 17 years old woman with GVHD associated to lichenoid and ulcerative lessions in the oral mucosa, which responded to the topical administration of a $0.1 \%$ tacrolimus ointment (Rev Méd Chile 2008; 136: 1570-3).

(Key words: Bone marrow transplantation; Graft us host disease; Tacrolimus)
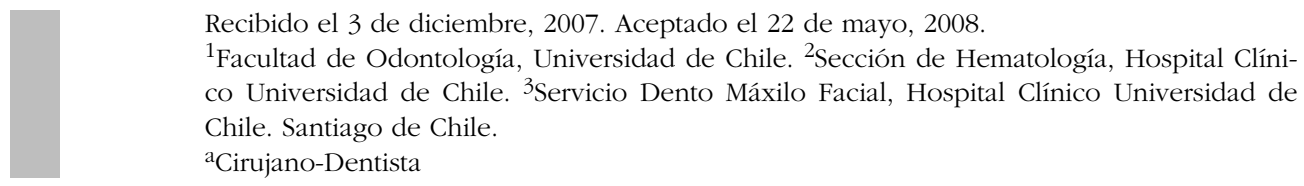
co Universidad de Chile. ${ }^{3}$ Servicio Dento Máxilo Facial, Hospital Clínico Universidad de Chile. Santiago de Chile.

${ }^{\mathrm{a} C i r u j a n o-D e n t i s t a}$

$\mathrm{E}^{1}$ trasplante de médula ósea (TMO) alogénico, es decir de donante HLA compatible, constituye el tratamiento de elección en primera o segunda línea para diversas enfermedades hematológicas como linfoma, leucemia y anemia aplásica. Las personas que reciben TMO pertenecen generalmente a las dos primeras décadas de la vida $^{1}$.

Existen diversas complicaciones del TMO, entre las cuales se puede mencionar las reacciones por toxicidad a medicamentos inmunosupresores, las infecciones y la enfermedad de injerto contra

$\overline{\text { Correspondencia a: Dr. Gonzalo Rojas A. Olivos 943. Inde- }}$ pendencia. E mail: grojasalcayaga@yahoo.es huésped (EICH) ${ }^{1}$. En boca, las infecciones bucales recurrentes de HHV-1, la mucositis y las lesiones por EICH son las principales complicaciones que se asocian a morbilidad y mortalidad ${ }^{1-3}$.

La EICH se presenta en una forma aguda y crónica. Actualmente existe consenso que son las manifestaciones clínicas el criterio determinante para considerar al síndrome de EICH en su forma aguda o crónica ${ }^{4}$. En la forma aguda, el principal compromiso es cutáneo semejando las formas severas a la necrolisis tóxica epidérmica. También puede ser digestivo, caracterizado principalmente por síndrome diarreico, náuseas, vómitos, dolor abdominal y hepático con alza de la bilirrubina ${ }^{4}$. En la forma crónica existen diversas complicaciones, entre ellas la esclerodermia ${ }^{5}$ y la disfunción hepática ${ }^{1}$. Cada órgano presenta signos o síntomas diagnósticos de la fase crónica, es decir son 
propios de la EICH crónica y no requieren de pruebas complementarias ni compromiso de otros órganos. Entre los signos o síntomas diagnósticos se encuentra la poikiloderma y lesiones tipo liquen plano en piel, estenosis del tercio superior del esófago, estenosis vaginales y bronquiolitis obliterante en los pulmones ${ }^{4}$.

El compromiso de boca ocurre principalmente en la fase crónica de este trastorno ${ }^{6}$ y es variable en términos de frecuencia, existiendo reportes en los que se describe una baja frecuencia ${ }^{1}$ y otros donde la frecuencia es alrededor de 50\% de los pacientes con $\mathrm{EICH}^{7}$. Las principales alteraciones corresponden a lesiones liquenoides o ulcerativas de mucosa bucal, asociadas con dolor intenso. También se observan fenómenos de xerostomía, queilitis angular y glositis ${ }^{8-12}$. En boca, los signos diagnósticos son lesiones de mucosa bucal tipo liquen plano, placas hiperqueratósicas y restricciones de la apertura bucal por esclerosis 5 .

Histopatológicamente las lesiones bucales se caracterizan por hiperparaqueratosis, degeneración del estrato basal del epitelio, infiltrado linfocitario subepitelial, fibrosis de la lámina propia y atrofia de las glándulas salivales menores ${ }^{8,10}$.

El control de las lesiones bucales, principalmente ulceraciones, es fundamental debido a que pueden constituirse en puerta de entrada para microorganismos comensales de la flora bucal hacia el torrente sanguíneo y determinar un riesgo de sepsis ${ }^{10}$. Los cuidados locales consisten básicamente en el uso de antisépticos como clorhexidina al 0,12\%, uso de antimicóticos si es necesario, dieta no irritante, corticoides tópicos (betametasona, clobetasol), anestésicos locales y medidas de higiene oral las que incluyen uso de cepillado suave y pasta de dientes indicada en casos de xerostomía, en vez de la pasta de uso habitual ${ }^{8-10}$.

\section{CASO CLÍNICO}

En septiembre de 2006 acudió al Servicio DentoMáxilo-Facial del Hospital Clínico de la Universidad de Chile, una paciente de 17 años, estudiante, derivada por Servicio de Hematología por presentar lesiones blanquecinas en mucosa bucal.

La paciente tenía el antecedente de anemia aplásica severa diagnosticada en 2005, la que se atribuyó a un derivado fenotiacínico y por lo cual fue sometida a trasplante de médula ósea (TMO) alogénico. Presentó las primeras manifestaciones de EICH agudo, con compromiso predominante cutáneo el día +42 , manifestado como lesión máculo-pápulo eritematosa de tronco y extremidades con biopsia compatible con EICH agudo, momento en que se administró asociación de corticoides (prednisona $20 \mathrm{mg} / \mathrm{dia}$ ) con ciclosporina, reemplazándose luego la ciclosporina por tacrolimus, $3 \mathrm{mg} /$ dia vía oral, debido a toxicidad neurológica de la primera. Las lesiones de la mucosa oral aparecieron en forma más tardía y su primera descripción aparece en la evolución del día +310 .

En el momento del examen clínico, las lesiones bucales comprometían casi la totalidad de la mucosa, pero se manifestaban mayormente en cara interna de labios, cara interna de mejilla y cara ventral de lengua. Las lesiones eran de color blanquecino, con aspecto reticular y no se desprendían al raspado (Figura 1). La paciente no refería síntomas asociados.

Con la hipótesis diagnóstica de compromiso de mucosa oral por enfermedad de injerto contra huésped se procedió a realizar biopsia incisional de mucosa de cara interna de labio inferior, lugar en el cual las lesiones eran manifiestas.

$\mathrm{El}$ informe histopatológico fue compatible con EIVH. Se describió un epitelio de revestimiento plano pluriestratificado hiperparaqueratinizado y con hiperplasia agujiforme. Un estrato basal con desorganización celular y en el corion inmediatamente subyacente infiltración linfocitaria junto con vasos de neoformación y proliferación fibroblástica. También se describió leve infiltrado linfocitario periductal en glándula salival menor vecina (Figura 2).

Se indicaron medidas locales para disminuir el riesgo de infecciones y mantener adecuada humectación del medio bucal; clorhexidina al 0,12\% dos veces al día, sustituto de saliva de uso diario, además de instrucción de higiene oral.

Seis meses después la paciente fue controlada manifestando dolor en algunas zonas de la mucosa bucal, evidenciándose lesiones erosivas en el examen clínico. Se decidió incorporar en el esquema de tratamiento local, el uso de betametasona al $0,1 \%$ en plastibase, reforzando las medidas de higiene bucal. Sin embargo, las lesiones permanecieron y el dolor aumentó, por 


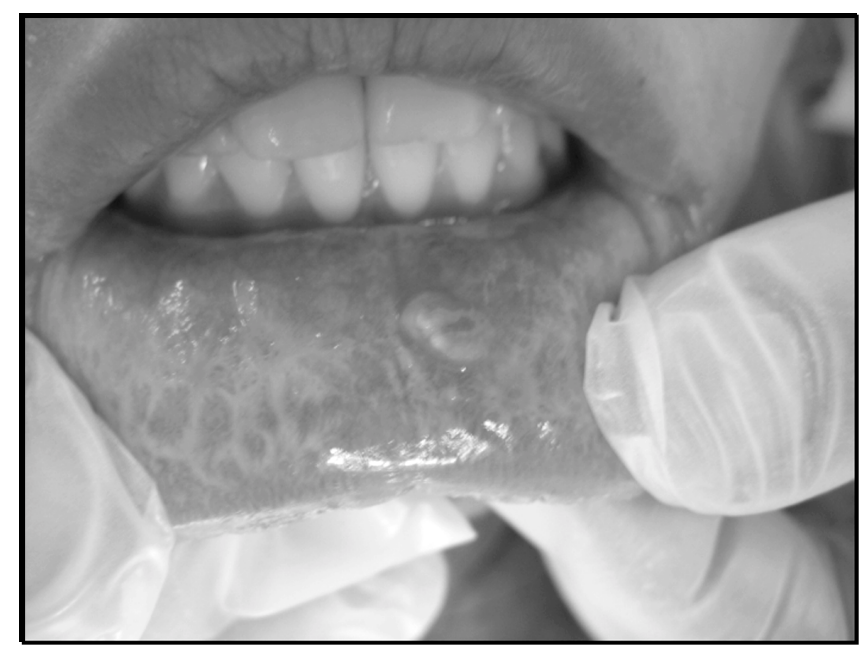

Figura 1. Lesiones en mucosa bucal características de EIVH. En la figura se pueden observar las lesiones blanquecinas reticuladas en mucosa bucal, semejantes al liquen plano oral.

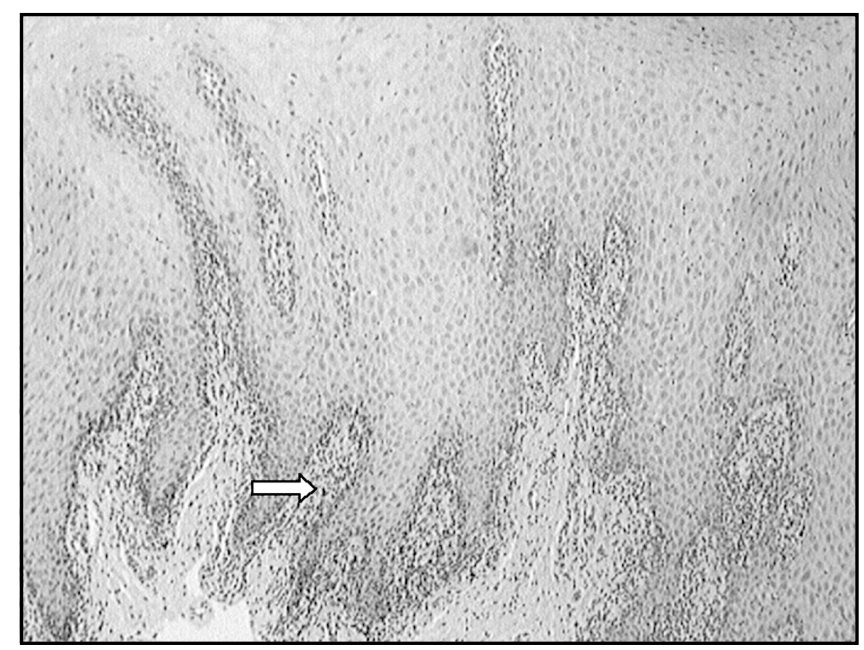

Figura 2. Aspectos histopatológicos. En la figura se puede observar la hiperplasia epitelial y el infiltrado linfocitario subepitelial (indicado con flecha). Aumento 10x. Hematoxilina-eosina.

lo cual se cambió por tacrolimus $0,1 \%$ en aplicación tópica 3 veces al día, agregándose además miconazol 2\% (Daktarin Gel) de aplicación tópica, 3 veces al día. Además se sustituyó la clorhexidina al $0,12 \%$ por una concentración más baja, 0,05\%, dado que la paciente le costaba tolerar la primera por provocarle ardor al momento de usarla. Después de una semana las lesiones remitieron y la paciente no presentaba dolor ni dificultades para alimentarse.

\section{Discusión}

Siempre se debe considerar la posibilidad del compromiso de mucosa bucal en la EICH y conocer las medidas locales a indicar. Las complicaciones bucales pueden impedir una adecuada alimentación e hidratación, o pueden generar complicaciones sistémicas ${ }^{10}$. En el caso de nuestra paciente, las lesiones inicialmente liquenoides evolucionaron hacia el desarrollo de úlceras, por lo que hubo que modificar el tratamiento y mantener un control periódico. Si bien el tratamiento es primordialmente sistémico para el control de las lesiones, el apoyo terapéutico local es imprescindible y tiene como objetivo mantener la boca con baja carga bacteriana, hidratar las mucosas, aliviar síntomas de ardor o dolor y prevenir o controlar lesiones erosivas/ulcerativas. En el presente caso y en un primer momento se indicó colutorios de clorhexidina al 0,12\% como agente antiséptico, más reforzamiento de las medidas de higiene bucal. También es posible usar clorhexidina al $0,05 \%$ en caso de ser poco tolerada una concentración mayor.

Como además se ha descrito compromiso de glándulas salivales en la EICH, el que se manifiesta como hiposalivación ${ }^{12}$, también se indicó uso de sustitutos de saliva en forma de recetario magistral, ya que la paciente relató sensación de boca seca (xerostomía). Cuando existen lesiones ulceradas se recomienda el uso de betametasona o tacrolimus en aplicación tópica, ambos al 0,10\% por un periodo de 15 días. En este caso, por no existir lesiones ulcerativas en el momento del primer examen no fue necesaria la indicación inmediata, pero se informó a la paciente que en la eventualidad de aparición de tales lesiones debía volver a consultar. A los seis meses acudió por presentar lesiones erosivas, momento en el que se decide incorporar el uso de betametasona al $0,1 \%$. Se prefirió la 
betametasona en vez del tacrolimus debido a que las lesiones se apreciaron bastante limitadas y porque el tacrolimus favorece el desarrollo de candidiasis oral. Sin embargo, si las lesiones no responden al uso de betametasona, se indica la sustitución por tacrolimus tópico ${ }^{13}$, tal cual ocurrió en esta situación. Se debe tener cuidado al momento de diagnosticar las lesiones erosivas y ulcerativas, perfectamente podrían confundirse con la reactivación de un herpes recurrente intraoral, en tal caso los inmunosupresores locales están contraindicados. Sin embargo, el aspecto de la lesión y su localización anatómica es importante de considerar. El herpes se presenta, al menos en una etapa inicial, como pequeñas vesículas que van coalesciendo y, en general, su ubicación está restringida a la mucosa masticatoria, es decir paladar y encía adherida ${ }^{4}$. En la paciente las lesiones eran úlceras extensas y sin antecedente

\section{REFERENCIAS}

1. Castro CG, Gregianin LJ, Brunetto Al. Clinical and epidemiological análisis of bone marrow transplantation in a pediatric oncology unit. J Pediatr 2003; 79: 413-22.

2. Anderson PM, Ramsay NKC, Shu XO, Rydholm N, Rogosheske J, Nicklow R et al. "Effect of low-dose oral glutamine on painful stomatitis during bone marrow transplantation". Bone Marrow Transplantation 1998; 22: 339-44.

3. Gómez R, Antuines M, Napier L, Netto J, Moraes De Azevedo W, De Marco L et al. Oral Recurrent human herpes virus infection and bone marrow trasplantation survival. Oral Surg Oral Med Oral Pathol 2001; 91: $552-6$

4. Filipovich A, Weisdorf D, Pavletic S, Socie G, Wingard J, LEE S ET AL. "National Institutes of Health Consensus Development Project on Criteria for Clinical Trials in Chronic Graft-versus-Host Disease: I. Diagnosis and Staging Working Group Report". Biology of Blood and Marrow. Transplantation 2005; 11: 945-56.

5 Skert C, Patriarca F, Sperotto A, Cerno M, Filí C, Zaja F ET AL. Sclerodermatous chronic graft-versus-host disease alter allogenic hematopoietic stem cell transplantation: Incidente, predictors and outcome. Haematologica 2006; 91: 258-61.

6. Neville B, Damm D, Allen C, Bouquot J. Dermatologic Diseases. En: Oral and Maxillofacial Pathology. WB Saunders Company. Philadelphia, Pennsyllvania. USA. 2002; 685-6. de formación de vesícula, con ubicación tanto en mucosa masticatoria como mucosa de revestimiento.

En el caso presentado es probable que las lesiones bucales estuviesen bien controladas en un primer momento debido a que la paciente se encontraba en tratamiento con inmunosupresores sistémicos (prednisona y tacrolimus). En la medida que se disminuyan las dosis de inmunosupresores sistémicos, debido a la buena evolución de la salud general del paciente, es necesario reforzar con la aplicación de inmunosupresores locales para prevenir la aparición de lesiones que comprometan la mucosa bucal.

Obviamente el trabajo interdisciplinario es fundamental en el caso presentado para un manejo terapéutico que permita a la paciente mantenerse en una adecuada situación de salud y tener una mejor calidad de vida.

7. Treister nS, Woo SB, O'Holleran EW, Lehman LE, Parsons SK, Guinan EC. Oral chronic graft-versusdisease in pediatric patients after hematopoietic stem cell transplantation. Biol Blood Marrow Transplant 2005; 11: 721-31.

8. De la Rosa-García E, Bologna-Molina R, Vega-GonzÁLEz MTJ. Graft-versus-host disease, an eight case report and literatura review. Med Oral Patol Oral Cir Bucal 2006; 11: E486-92.

9. Domínguez-Reyes A, Aznar-Martín T, Barnería-Leache E, Cabrera-Suárez E. Manifestaciones orales en la enfermedad injerto contra huésped (EICH). Presentación de un caso. Med Oral 2003; 8: 361-5.

10. Miranda Franca C, Domínguez-Martins M, Volpe A, Pallota R, Soares De Araujo N. Severe oral manifestations of chronic graft-vs-host disease. JADA 2001; 132: 1124-7.

11. Nicolatu-Galitis O, Kitra V, Van Vliet-Constantinidou C, Peristeri J, Goussetis E, Petropoulos D et al. The oral manifestations of chronic graft-versus-host disease (cGVHD) in paediatric allogenic bone marrow transplant recipients. J Oral Pathol Med 2001; 30: 148-53.

12. Alborghetti Mr, Correa M, Adam RL, Metze K, Coracin F, De Souza C, Cintra ML. "Late effects of chronic graft-vs-host disease in minor salivary glands". J Oral Pathol Med 2005; 34: 486-93.

13. Riaño A, Martino R, iglesias me, Garatea J. "Topic tacrolimus, alternative treatment for oral erosive lichen planus resistant to steroids: A case report". Med Oral Patol Oral Cir Bucal 2006; 11: E462-6. 